\title{
Welfare state winners and losers in ageing societies
}

\author{
Miguel Sánchez-Romero ${ }^{1}$, Gemma Abío ${ }^{2, *}$, Montserrat Botey ${ }^{3}$, \\ Alexia Prskawetz ${ }^{1}$, Jože Sambt ${ }^{4}$, Meritxell Solé Juvés ${ }^{2}$, Guadalupe Souto ${ }^{5}$, \\ Lili Vargha ${ }^{6}$ and Concepció Patxot ${ }^{2}$
}

\section{Abstract}

In this paper, we analyse the impact of population ageing on the sustainability and the intergenerational fairness of public fiscal policy in three selected European countries (Austria, France, and Spain). We use NTA and NTTA data, and introduce these data into a large-scale general equilibrium OLG model with realistic assumptions regarding demographic trends and changes in population structure. The results for sustainability show a sharp increase in the share of public expenditure to GDP for the main programmes of the welfare state. In the three countries analysed, public policies (e.g. education, health care, and pension benefits) redistribute income from younger individuals to older individuals. Our findings indicate that these policies redistribute more resources to older individuals in Spain and fewer resources to older individuals in Austria. We consider the effects of several reform scenarios, including simulations in which the statutory retirement age is raised and the tax base for financing health care expenditures are changed. We also describe the consequences of the population having a fixed level of educational attainment.

\footnotetext{
${ }^{1}$ Wittgenstein Centre for Demography and Global Human Capital, Vienna Institute of Demography, Austrian Academy of Sciences, Vienna, Austria

and

TU Wien, Institute of Statistics and Mathematical Methods in Economics, Austria

${ }^{2}$ Universitat de Barcelona, Departament d'Economia, Facultat d'Economia i Empresa, Avda. Diagonal 696, 08034 Barcelona, Spain

${ }^{3}$ Université d'Orléans- LIEPP Sciences Po, France

${ }^{4}$ University of Ljubljana, Faculty of Economics, Ljubljana, Slovenia

${ }^{5}$ Universitat Autònoma de Barcelona, Spain

${ }^{6}$ Hungarian Demographic Research Institute, Budapest, Hungary

*Correspondence to: Gemma Abío, abio@ub.edu
} 


\section{Introduction}

It is widely acknowledged that population ageing poses a challenge to the welfare state by exerting severe fiscal pressure on its sustainability. Indeed, the age composition of the population directly affects the three main pillars of the welfare state: namely, pensions, education, and health. Over the course of the 20th century, European countries have introduced public pension systems that mainly operate on a pay-as-you-go (PAYG) basis, and that are financed through social contributions. Meanwhile, public education systems are mostly financed through general taxes, usually also on a (non-explicit) PAYG basis. The financing of public health care systems varies across countries. Social security health care models are mainly financed through contributions, while national health systems tend to be financed through general taxes. However, regardless of the method used, the financing of most of these programmes is not balanced from an intertemporal point of view. Given that tax payments are concentrated at working ages whereas public benefits are received primarily at dependent ages, the rapid ageing of the European population could threaten the long-term viability of these programmes.

The Overlapping Generations Model (OLG) is a framework that can be used to investigate the impact of population changes on the sustainability of public budgets. In this model, households make their lifecycle decisions at different ages, while interacting with other agents. In this paper, we follow the accounting framework in Bommier and Lee (2003), who studied the static and dynamic properties of a productive market economy in a continuous time OLG model with a general age schedule of mortality. These authors discussed the dimensions of the sustainability accounting scheme, and examined the dynamic link between cross-sectional and longitudinal accounts. From a cohort lifecycle perspective, they measured the net contribution of each cohort to the public coffers using the present value of net expected benefits at birth. This present value is defined as the survival-weighted discounted sum of benefits received minus taxes paid at each age for each generation along its entire lifecycle. If the present value equals zero for every birth cohort, the transfer system is said to be "lifecycle balanced". From a cross-sectional perspective, they defined the population-weighted average flow of a transfer system in a given year as the sum at each age of the net benefits received from the transfer system by all individuals of that age, divided by the size of the population in the corresponding year. If the average flow is equal to zero for every year, it is said to be "population balanced"; i.e. all of the transfer system's flows aggregate to zero at any time. While this would be the case in a perfectly balanced PAYG system, the government can escape this constraint by issuing public debt or accumulating wealth. Interestingly, in a context in which the population structure is changing, intertemporal sustainability is not guaranteed, even when these two conditions are met.

An extensive list of indicators of the sustainability of a public budget can be found in the literature. Gal and Monostori (2014) distinguished between crosssectional and long-term (or intertemporal) indicators. Cross-sectional indicators 
refer to variables (mainly taxes and benefits) of the same year (as in the populationbalanced case mentioned above), while long-term indicators refer to variables of many periods. A measure that synthetises these two types of indicators is the intertemporal budget constraint of the government, which takes into account not only the explicit debts of the past, but the implicit (and perhaps unfunded) future compromises that affect current and future generations. A clear example of such a measure is social security wealth (debt); i.e. the implicit wealth (debt) accumulated by a PAYG pension system. When referring to the whole public budget, the sustainability gap indicator is often used. In the generational accounting literature, this indicator refers to the residual in the intertemporal budget constraint of the government; i.e. to the portion of the current plus the foreseeable debt that is not covered by foreseeable taxes. ${ }^{1}$ These kinds of indicators can then be translated into necessary tax or transfer adjustments (like the tax gap indicator).

Computing sustainability indicators requires a considerable amount of data. Fortunately, the recent development of National Transfer Accounts (NTA), which introduce the age dimension to National Accounts (NA), has significantly improved data availability (Lee and Mason 2011). NTA provide age profiles (in a given year) for all the NA categories, including taxes and transfers. ${ }^{2}$ Moreover, as National Time Transfers Accounts (NTTA) incorporate time transfers, they provide a complete picture of all of the economic flows that are taking place in the economy (through both market and non-market activities) in a given year (Donehower 2014). The availability of these data opens up the possibility of investigating how changes in the age structure of the population affect the sustainability of the welfare state.

Bommier et al. (2010) used the NTA data to measure the net present value of monetary transfers in a partial equilibrium framework. In this paper, we take a similar approach, using a large-scale general equilibrium OLG model based on realistic assumptions regarding demographic trends and changes in population structure. In particular, we use the model developed in Sánchez-Romero et al. (2017) to derive results on the sustainability and the intergenerational fairness of public transfers in three European countries (Austria, France, and Spain). These countries differ in terms of the strength of their demographic transition, their path of development, and the generosity of their welfare state programmes. ${ }^{3}$

In order to undertake a comprehensive sustainability analysis that includes the cohort perspective, we rely on both NTA and NTTA data. Using NTTA data allows us to consider the labour supply decision, while taking into account the cost of raising children. Specifically, we start with the historical reconstruction of past NA

\footnotetext{
1 See Bonin (2001). See also Lee et al. (2017), who developed a full generational accounting method that also includes private transfers.

2 NTA data are available at www.ntaccounts.org, and more data for EU countries are also available at the AGENTA EU project web page http://www.agenta-project.eu and at the AGENTA Data Explorer http://dataexplorer.wittgensteincentre.org/nta/. For more information on the methodology, see UN (2013).

3 See the Appendix for details.
} 
data, and combine these data with the age profiles obtained from NTA and NTTA. This approach allows us to assess where past, present, and future generations are in the demographic transition process.

Interestingly, the strength of the effects of ageing on welfare state sustainability depends on a characteristic that has long been overlooked: namely, the extent to which social transfers are directed to people in the two stages of economic dependency along the lifecycle (childhood and old age). Indeed, upward transfers (from younger to older ages) suffer from lower returns as the population ages, while the opposite is the case for downward transfers (from adult to younger ages) like education. By introducing NTA age profiles, the model allows us to assess the consequences of the age composition of these social transfers.

The paper is organised as follows. Section 2 briefly describes the model and presents the general trends in sustainability. Section 3 is devoted to cohort analysis. The intergenerational fairness of public fiscal policy is evaluated by comparing the net contributions to public coffers of subsequent cohorts, who are affected differently by the tax adjustments that are likely to become necessary as the population structure changes. Section 4 considers the effects of several reform scenarios. In particular, we simulate the impact of delaying the retirement age and the impact of modifying the tax base for health care expenditures. We also look at the effects of a shift in the educational attainment levels of the population. Finally, Section 5 concludes with a final discussion.

\section{Sustainability of welfare state programmes}

\subsection{The model}

In the standard OLG model, individuals who differ only by age decide how to distribute their lifetime resources between consumption and savings along their lifecycle. The model we use differs from the standard model in several respects. ${ }^{4}$ It is a large-scale model $^{5}$ that incorporates realistic demography ${ }^{6}$ (Bommier and Lee 2003), with households consisting of an adult who may live up to a maximum of 105 years, facing mortality risk as in Yaari (1965), and having a number of dependent children. The composition of each household varies by age and across cohorts based

\footnotetext{
4 Technical details are explained in Sánchez-Romero et al. (2017). See also Sánchez-Romero et al. (2018) for an earlier version of the model measuring the past impact of demographic dividends in Spain.

5 The starting point for the literature on large-scale OLG models is Auerbach and Kotlikoff (1987). Large-scale OLG models are simulations with detailed age groups, usually broken down by single years. By contrast, the models used in theoretical analysis usually simplify the lifecycle to three periods of life (childhood, adulthood, and old age).

6 This expression refers to the existence of dispersion of the age at death.
} 
on the observed and projected fertility and mortality patterns. Household heads are assumed to be heterogeneous in terms of their level of education, which is randomly assigned to each individual at birth. The level assigned is one of three ISCED levels developed by UNESCO: ISCED 0-2 (lower secondary education or less), ISCED 3-4 (upper secondary education), and ISCED 5+ (tertiary education). ${ }^{7}$ Hence, in each year, individuals differ according to their age, fertility, mortality, and educational attainment.

Individuals derive utility from consumption goods, leisure, and the time they spend taking care of their children. Consumption goods can be produced in the market (using physical and human capital as input factors) or at home (combining time and intermediate market goods). In addition to consuming home-produced and market goods, the households in our model decide how much time they spend on work (in the market and at home), on childcare, and on leisure.

The government in our model provides public education, health care, pension benefits to retirees, and other public programmes; and distributes accidental bequests to surviving individuals. Both public in-kind and in-cash transfers are financed through a balanced PAYG system via consumption taxes, capital income taxes, labour income taxes, and social contributions.

We explicitly consider not only public transfers, but family transfers to children, including time transfers. Age profiles of all transfers are taken from the NTA and the NTTA datasets (Istenič et al. 2016, 2017). Using historical NA data and NTANTTA profiles, the model produces a complete age-time matrix of benefits and taxes for each year and birth cohort, which we then use to develop an analysis from both a cross-sectional and a longitudinal point of view. In particular, the model allows us to trace the annual evolution of expenditures affected by the age structure of the population, while taking into account the evolution of transfers to the past, the current, and the future population. ${ }^{8}$ These transfers affect the tax levels that are required to balance the public budget every year. The model therefore captures the annual tax adjustments that will be needed in the future to meet the projected increase in expenditures caused by the ageing of the population. Hence, we are able to gauge the overall sustainability of the public finances by obtaining a crosssectional annual version of the tax gap indicator.

\subsection{Cross-sectional analysis}

In this section, we focus on cross-sectional sustainability indicators. In particular, we analyse the annual evolution of public benefits, which we obtain by combining

\footnotetext{
7 The assignment is done in order to reproduce the observed educational distribution taken from the Wittgenstein Centre Database (2015).

8 Population projections are derived to replicate those used by the Ageing Working Group of the European Commission coming from EUROSTAT. See Sánchez-Romero et al. (2017). Figure A.2 in the Appendix shows the resulting evolution of the dependency ratio.
} 
Figure 1:

Public expenditures as a share of GDP in Austria, France, and Spain
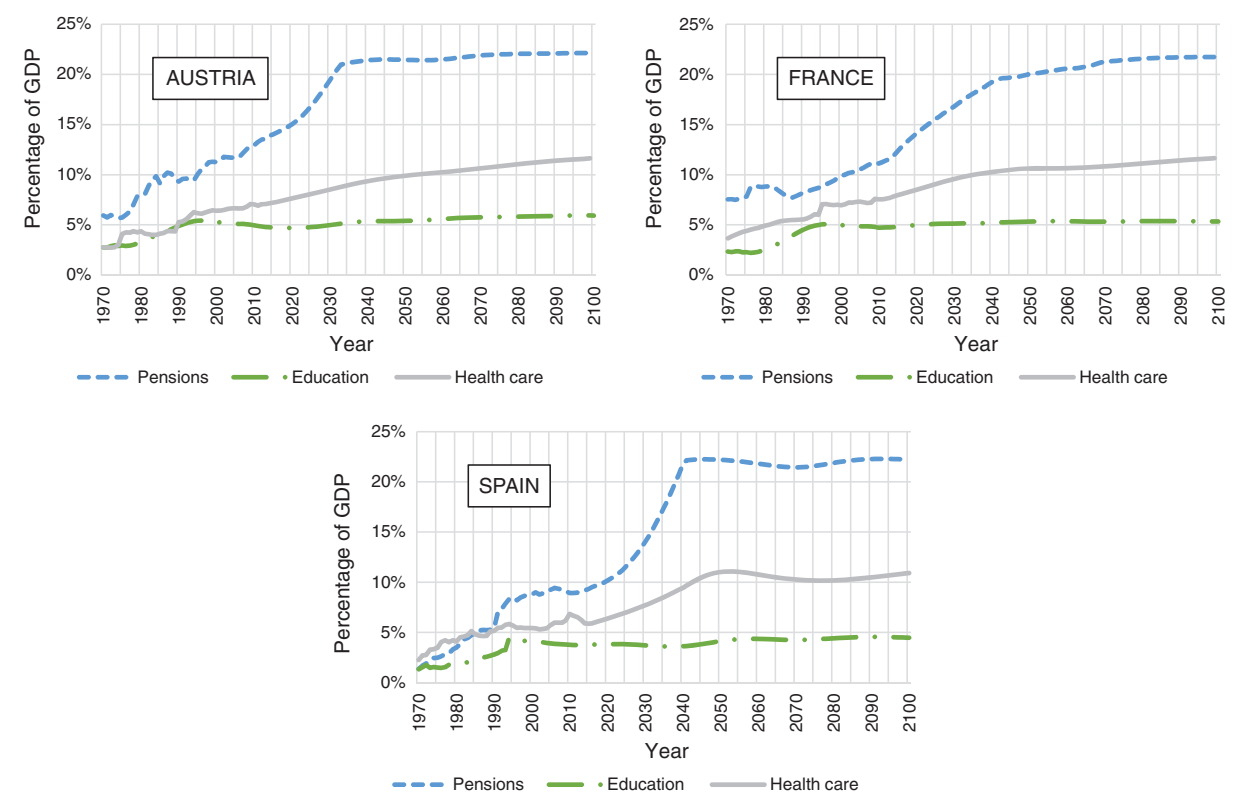

Source: Authors' calculations using data from OECD (2017).

NTA profiles with the observed historical aggregates of public expenditures, and the tax adjustments needed to achieve an annual balance of a budget with PAYG constraints. ${ }^{9}$

Figure 1 shows the historical evolution (for 1970-2015) and the projected evolution of the ratio of public expenditures to GDP in Austria, France, and Spain through the 21st century. As populations age, an increasingly large share of resources will be devoted to the three main welfare state programmes (retirement pensions, education, and health care). In the three countries, the largest increases in expenditures will be for pensions, which are projected to account for more than one-fifth of GDP by the time members of the baby boom generation have reached retirement ages. ${ }^{10}$ Indeed, under current models (see Sánchez-Romero et al. 2017), social security contributions will adjust each year to guarantee that the level of pension benefits is maintained for all retired individuals, but only up to a maximum contribution tax rate of $35 \%$. After this value is reached, benefits are adjusted downwards in order to balance the budget. This adjustment will prevent pension

9 The NTA age profiles of public expenditures are summarised in the Appendix.
10 Only contributory retirement pensions are considered. 
expenditures as a share of GDP from reaching even higher values in the second half of the century. Health care expenditures as a share of GDP are also projected to more than double in the three countries, reaching values of around 11-12\% in 2100. Spending on the other main pillar of the welfare state, education, is not projected to change substantially over the $21^{\text {st }}$ century: i.e. education expenditures will remain at roughly 5-6\% of GDP, with slightly lower values in Spain.

Not surprisingly, the programmes involving transfers to the elderly are expected to grow relative to the national income as populations age. In the case of health care, the age profiles have similar shapes in the three countries considered, with higher expenditures at birth and very high expenditures at older ages. ${ }^{11}$ The projection that the youth dependency ratio will shrink as the old-age dependency ratio rises further confirms that total expenditures are highest at higher ages. Hence, budgets are expected to increase as a consequence of the demographic transition. ${ }^{12}$ For education, it appears that the effects of the educational transition compensate for the decline in the number of children. Thus, the weight of education programmes is projected to remain rather constant over time.

It is assumed that all public programmes are financed through a balanced PAYG system. Apart from the pension system's budget constraint, there is another key constraint on government budgets: namely, that most public expenditures are financed through general taxes (i.e. consumption, capital income, and labour income taxes). Although it would seem more realistic to account for the possibility of public debt, and to introduce debt into the model by considering the government's intertemporal budget constraint, here we stress the demographic dependency of expenditures by imposing an annually balanced system in all programmes. ${ }^{13}$ Table 1 shows the weight of each public expenditure programme and the value of the different tax rates needed to balance the budget of the programme at three moments in time for the three countries considered: namely, in the year 2015; 30 years earlier (1985), when the ageing process had just begun; and 30 years later (2045), when the effects of the ageing process have spread throughout the economy.

Table 1 highlights the fact that the welfare state was developed later in Spain than in the other two countries. Thus, in 1985, the shares of pension and education expenditures in GDP were lower in Spain than in Austria and France (4.9 and 2.3 in Spain versus 9.1 and 4.1 in Austria and 8.0 and 3.4 in France, respectively). The differences in pension expenditures had shrunk by 2015 and are projected to reverse by 2045 . This is largely because even though Spain has relatively low benefit levels, its population is ageing more rapidly than the populations of France and Austria. Moreover, because the educational transition started later in Spain and is projected

\footnotetext{
11 See Figure A.2 in the Appendix.

12 Interestingly, the NTA estimates indicate that in most countries, transfers to older people exceed those to children, even in per capita terms (see Patxot et al. (2012) and Abío et al. (2015)).

13 For comparability reasons, we opt for this stylised simulation, while ignoring the differences in the health care financing models in the three countries.
} 
Table 1:

Public expenditures relative to GDP and tax rates in Austria (AUT), France (FRA), and Spain (ESP)

\begin{tabular}{|c|c|c|c|c|c|c|c|c|c|}
\hline \multirow{2}{*}{$\begin{array}{c}\text { Year } \\
\text { Country }\end{array}$} & \multicolumn{3}{|c|}{1985} & \multicolumn{3}{|c|}{2015} & \multicolumn{3}{|c|}{2045} \\
\hline & AUT & FRA & ESP & AUT & FRA & ESP & AUT & FRA & ESP \\
\hline \multicolumn{10}{|c|}{ Public expenditure to GDP (\%) } \\
\hline Pensions & 9.1 & 8.0 & 4.9 & 14.0 & 12.3 & 9.3 & 21.5 & 19.7 & 22.2 \\
\hline Education & 4.1 & 3.4 & 2.3 & 4.7 & 4.8 & 3.7 & 5.4 & 5.3 & 3.8 \\
\hline Health & 4.0 & 5.4 & 4.8 & 7.2 & 7.9 & 5.9 & 9.6 & 10.5 & 10.5 \\
\hline Other ${ }^{\mathrm{a}}$ & 8.8 & 11.5 & 6.2 & 6.3 & 8.9 & 8.3 & 6.2 & 8.6 & 8.2 \\
\hline \multicolumn{10}{|l|}{ Tax rate $(\%)$} \\
\hline $\begin{array}{l}\text { Social sec. } \\
\text { contributions }\end{array}$ & 17.6 & 15.4 & 7.6 & 25.3 & 21.5 & 14.7 & 35.0 & 33.0 & 35.0 \\
\hline Consumption & 14.2 & 18.2 & 9.7 & 14.0 & 19.2 & 12.6 & 17.2 & 23.3 & 17.6 \\
\hline Capital income & 15.7 & 20.0 & 18.2 & 16.2 & 28.4 & 31.3 & 17.9 & 29.2 & 35.9 \\
\hline Labour income & 10.4 & 12.1 & 7.4 & 12.7 & 12.0 & 9.4 & 15.0 & 13.9 & 12.0 \\
\hline
\end{tabular}

Note: ${ }^{a}$ Other expenditures include in-kind expenditures on defense, justice, and administration. However, other social benefits provided in cash are excluded from our analysis.

to continue through the latter decades of the 21st century, public expenditures on education in 2045 are projected to be lower in Spain than in the other two countries. With respect to health care, Austria is the country with the lowest expenditure levels in both 2015 and 2045. This is mainly because in the Austrian age profile, the level of public health benefits relative to labour income is lower than it is in Spain and France.

Regarding tax rates, we assume that the weight of each tax rate (on consumption, labour income, and capital income) observed in the baseline year is held constant in the future, and that this tax mix is adjusted proportionately every year thereafter to fund government consumption. In the case of social security contributions, the differences between the three countries in 1985 again reflect the distinct stages of development of the pension system at that point in time: i.e. the contribution levels in Spain were less than half the levels in the other two countries. Based on the modelling assumptions, social security contributions are projected to reach the upper limit of 35\% in Austria and Spain by 2045 (specifically, this limit is reached in 2034 in Austria and in 2041 in Spain); while in France, which is ageing more slowly, contributions are not projected to reach this limit until 2069. In Spain, consumption and labour income taxes were systematically lower in 1985 and 2015 than they were in the other two countries. However, the consumption tax is not projected to be lower in 2045, as larger adjustments are expected to become necessary in Spain as the population ages. Meanwhile, the capital income tax rate is highest in Spain 
over most of the study period, and is lowest in Austria throughout the period. In Section 4.2, the effects of future changes in the tax bases are discussed.

As Table 1 shows, tax rates are projected to increase in all three countries as the effects of ageing spread throughout the economy. This finding illustrates the challenges facing current public expenditure programmes, as it is clear that these transfer systems would become unsustainable if tax rates remained constant. The next section shows how these tax adjustments are projected to affect different generations. ${ }^{14}$

\section{Cohort analysis}

In this section, we assess the intergenerational impact of public transfers by measuring the levels of financial redistribution expected to occur through the public pension, education, and health systems. To do so, we take a longitudinal and cohort perspective, and calculate the lifetime-discounted survival-weighted benefits received and the lifetime-discounted survival-weighted taxes paid during the lifetime of each generation born between 1900 and $2100 .{ }^{15}$ The difference between these two figures is referred to as the net present value at birth of the transfer system. If this value is zero, the transfer system is actuarially fair. If it is the same for all birth cohorts, the system does not allow for any intergenerational redistribution. We first compute the present value of benefits and taxes at birth for each public programme separately, and then calculate the net present value for pension, education, and health care benefits combined. These present values are expressed relative to the present value of survival-weighted lifetime earnings, as this makes it easier to compare the values over time and to discern the relative cost of the system for each birth cohort.

\subsection{Present value of public benefits and taxes}

Figure 2 shows the present value at birth of pension benefits and taxes (i.e. social contributions) for cohorts born during the 21st century in Austria, France, and Spain. The three countries exhibit similar patterns for both series, with taxes reaching much higher values than benefits, and the gap between taxes and benefits widening for cohorts born further in the future. In France, this difference is always negative; which means that all generations have paid or are expected to pay more than they have received or are expected to receive over their lifecycle from the pension system. In Austria and Spain, however, there is a small positive gap between the present

\footnotetext{
14 Further results on the evolution of key variables can be found in Sánchez-Romero et al. (2017).

15 It should be noted that although we were able to capture the historical evolution of transfers in successive cohorts, we were unable to completely capture the time path of taxes by abstracting from the evolution of debt.
} 
Figure 2:

Present value at birth of public pension benefits and taxes
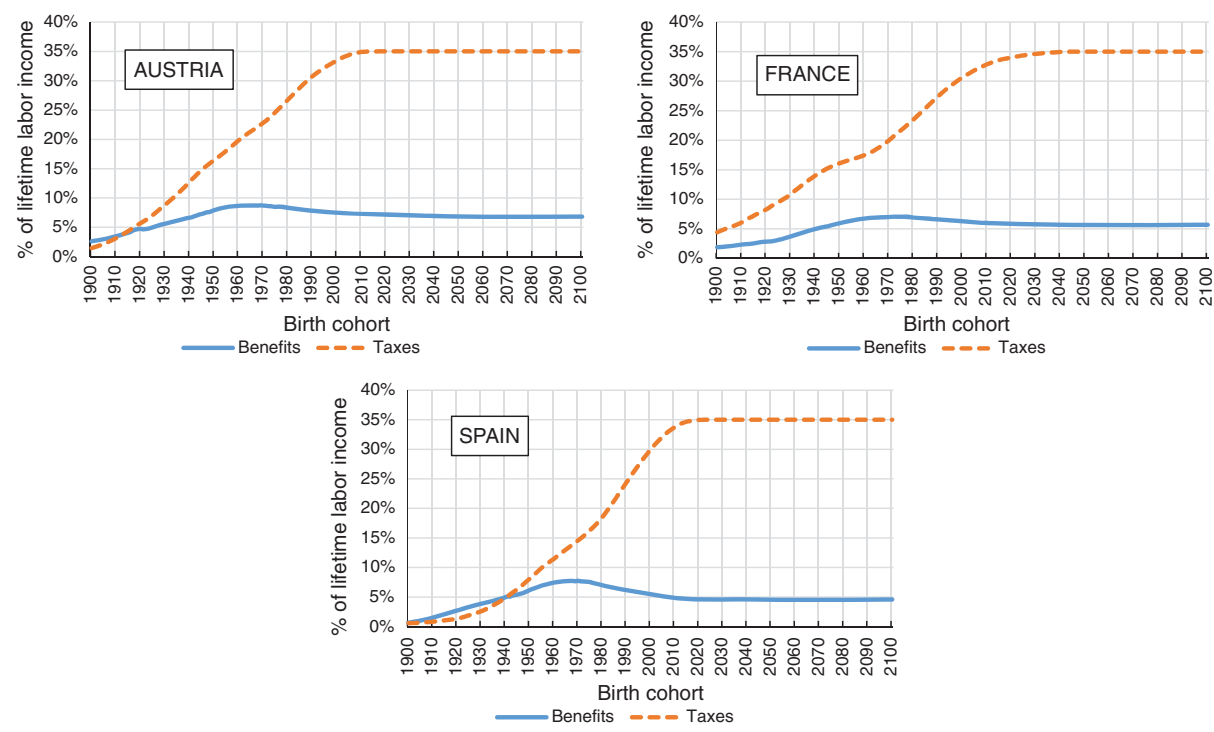

value of pension benefits and social security contributions for generations born during the 1900-1912 (Austria) and 1900-1940 (Spain) periods. These generations received a windfall gain from the public pension system. Because the system did not exist in the early $20^{\text {th }}$ century, these cohorts did not have to pay contributions during all of their working years. However, by the time these cohorts retired, the system was in place, and they were eligible to receive pension benefits. The cohorts born in 1900 in Austria and in 1924 in Spain received the largest gains, corresponding to $1.3 \%$ and $1.4 \%$ of lifetime labour income, respectively.

When analysing transfers from younger to older individuals, as in the case of the pension system, it is generally found that the present value of taxes paid is higher than that of benefits. This standard result is partly due to the effect of discounting. ${ }^{16}$ To understand the intuition of this effect, consider a transfer system in which an individual pays a fixed amount of money for 20 years during his/her working life, and then receives exactly the same amount of money during the following 20 years. When computing the present value at birth of taxes and benefits for this transfer system, we obtain a higher discounted value of tax payments than of transfer receipts, even though the monetary amount paid by an individual during his/her lifecycle is the same as the total amount $\mathrm{s} /$ he receives at the end of his/her life. This

\footnotetext{
16 This is also because the economy is subject to dynamic efficiency, which implies that the returns to savings are higher than the returns of the PAYG-financed public system.
} 
is because in an upward transfer system, tax payments occur earlier in life than transfer receipts, and are thus less discounted.

The finding that the gap between taxes and benefits is growing over birth cohorts is attributable to the share of beneficiaries increasing (due to population ageing) relative to the share of contributors, together with the assumption that the PAYG system is balanced annually by adjusting social security contributions, up to the maximum level of $35 \%$. In an ageing population, the decline in the support ratio implies that each generation of young individuals has to support an increasing number of elderly people. Hence, the net present value of pension benefits becomes smaller, and the rate of return in a PAYG pension system is reduced.

Figure 3 displays results for a public education system financed with the tax mix mentioned above. Since education benefits represent a transfer from parents to children, whereas pension benefits represent a transfer from children to parents, the picture changes completely, and the lifecycle accounts are mostly positive and increasing for future cohorts. The cohorts born between 1907 and 1943 in Austria and between 1927 and 1977 in Spain pay more in taxes for education than they receive in transfers, and thus have a negative net present value at birth for this programme. The largest losses correspond to $1.6 \%$ and $4.4 \%$ of lifetime earnings for the cohorts born in 1933 in Austria and in 1961 in Spain, respectively. The largest gains in these two countries are achieved by the cohorts born in 2100, amounting to $30.0 \%$ and $34.4 \%$ of lifetime labour income, respectively. In France, cohorts born before 1968 are almost in lifecycle balance, with a net present value near zero. The largest gains from public education in this country amount to $25 \%$ of lifetime earnings for the cohort born in 2100. In all three countries, cohorts born further in the future increasingly benefit from higher education, which translates into higher wages.

The lifetime-discounted survival-weighted benefits received from the health system and the corresponding taxes paid are displayed in Figure 4. As is the case for the pension system, the present value of taxes for this public programme is above the present value of benefits received by the majority of cohorts and countries. This is because the age profiles for health expenditures, derived from the NTA data report, show substantially higher values for the elderly. The only groups who do not follow this pattern of a higher present value of taxes are a few generations born at the beginning of the 20th century in Austria and France; although the maximum positive gap found for these cohorts is only $0.4 \%$ of lifetime labour income. In all countries, the present value at birth of benefits and taxes increases at a faster pace up to the 1970 birth cohort, and more gradually for the later cohorts.

In the case of Spain, the evolution of both benefits and taxes is less smooth due to the effects of the ageing of the baby boom generation and the lower fertility rate in the 21 st century. In Spain, the highest present values of benefits (18.0\%) and taxes $(24.5 \%)$, and the largest gap between them, are reached in the generation born in 2009 , who are projected to suffer a loss equivalent to $11.3 \%$ of lifetime labour income. Spaniards born between 1990 and 2020 are projected to suffer the greatest 
Figure 3:

Present value at birth of public education benefits and taxes
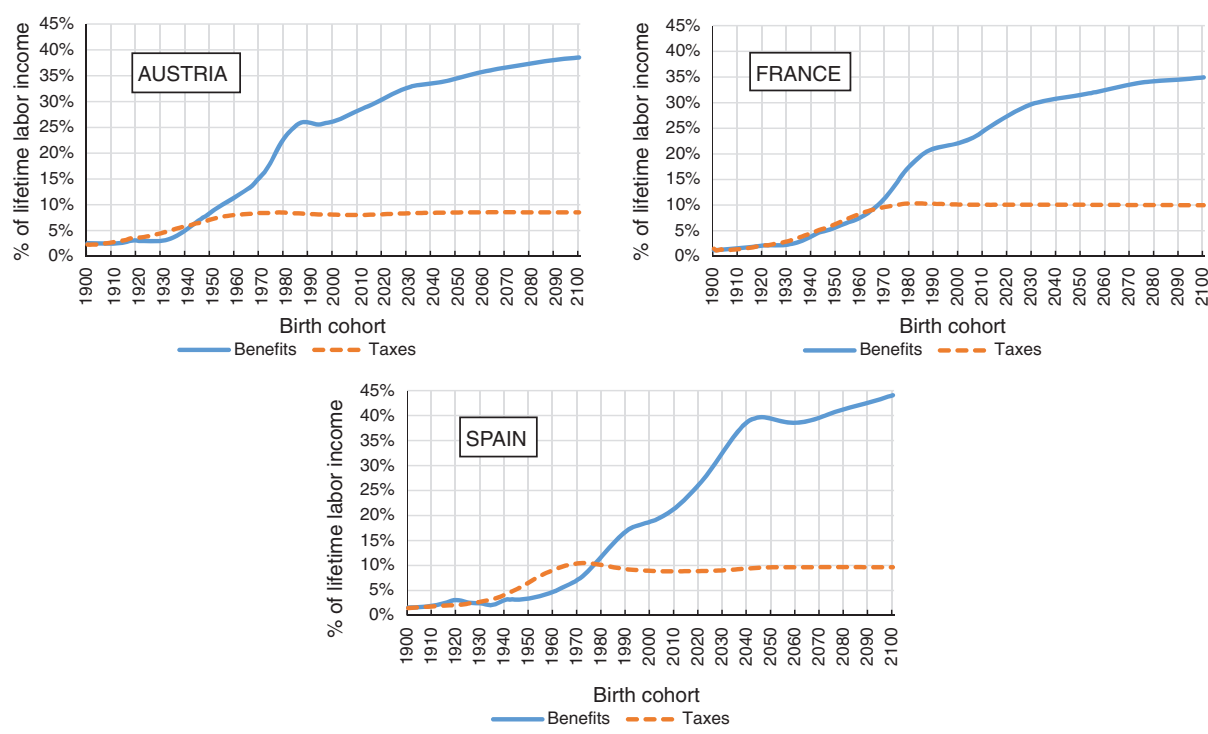

losses, as they will have to pay larger tax bills to fund the health care needs of the Spanish baby boomers.

In France, the present value at birth of health benefits rises up to $15.4 \%$ of lifetime earnings for the 2100 birth cohort, while the corresponding value for taxes in 2100 reaches $22.2 \%$ of lifetime labour income. The generations born after 1980 suffer similar losses (the difference between taxes paid and health benefits received), amounting to around $7 \%$ of lifetime earnings. Earlier generations have smaller gaps between health benefits and taxes. The maximum loss is observed for the 2007 birth cohort ( $7.8 \%$ of lifetime labour income). The lower rate of ageing in France explains these results.

The Austrian public health system achieves the highest degree of intergenerational fairness. As Figure 4 shows, the differences between the benefits received and the taxes paid for each cohort are relatively small (and rather similar within cohorts), ranging from $2 \%$ to $3.3 \%$ of lifetime labour income for all generations born in the 1950 s onwards. The present value at birth of taxes paid to fund public health in Austria reaches a maximum of $17.3 \%$ of lifetime earnings for the 2100 birth cohort, while the analogous figure for benefits is $14 \%$. These values are lower in Austria than in the other two countries because the scale of the Austrian age-specific health care profile is smaller. 
Figure 4:

Present value at birth of public health care benefits and taxes
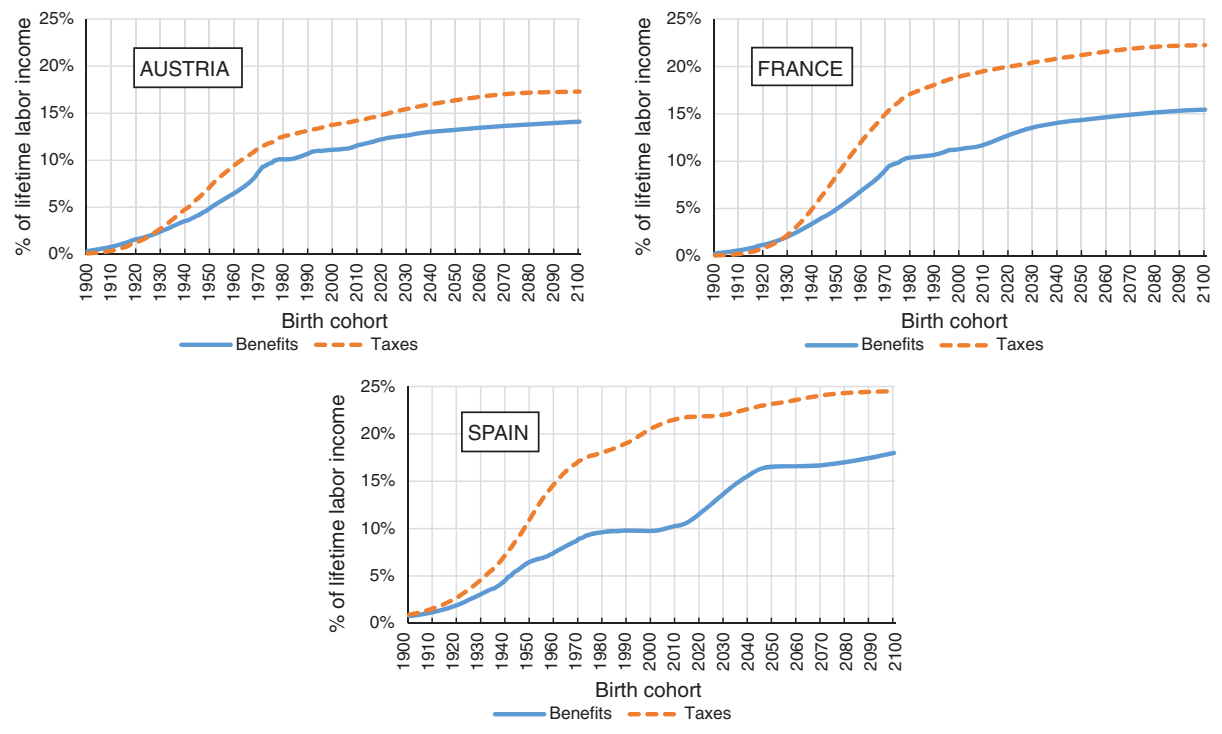

\subsection{Net present value of public benefits}

So far, we have analysed the net contributions of each generation relative to lifetime earnings for the three main pillars of the welfare state - pensions, education, and health care - that are of varying importance for different age groups. Next, we sum up the lifecycle accounts obtained for each public programme, and focus on the total net impact of those public transfers.

Figure 5 shows the present value at birth of net benefits received from the public sector for cohorts born in the 1900-2100 period in Austria, France, and Spain. In all three countries, the generations born at the beginning of the 20th century have the highest values. In general, these cohorts were not responsible for funding the expansions of the public pension, education and health care systems. The initial positive values for Austria are due to the modest net benefits obtained from the pension and health care systems. In the case of Spain, these early cohorts benefited greatly from the introduction of the social security programme, as they received pension benefits despite having contributed little or nothing to the system. Moreover, while these cohorts paid taxes to support the health care system, the combined net effect for these cohorts is positive. Positive values are observed in Austria and Spain for the birth cohorts up to 1913 and 1927, respectively.

Cohorts born in later years have lower net present values, mainly because benefit costs rose as the pension and health care systems were introduced and expanded. 
Figure 5:

Net present value at birth of public pensions, education, and health transfers

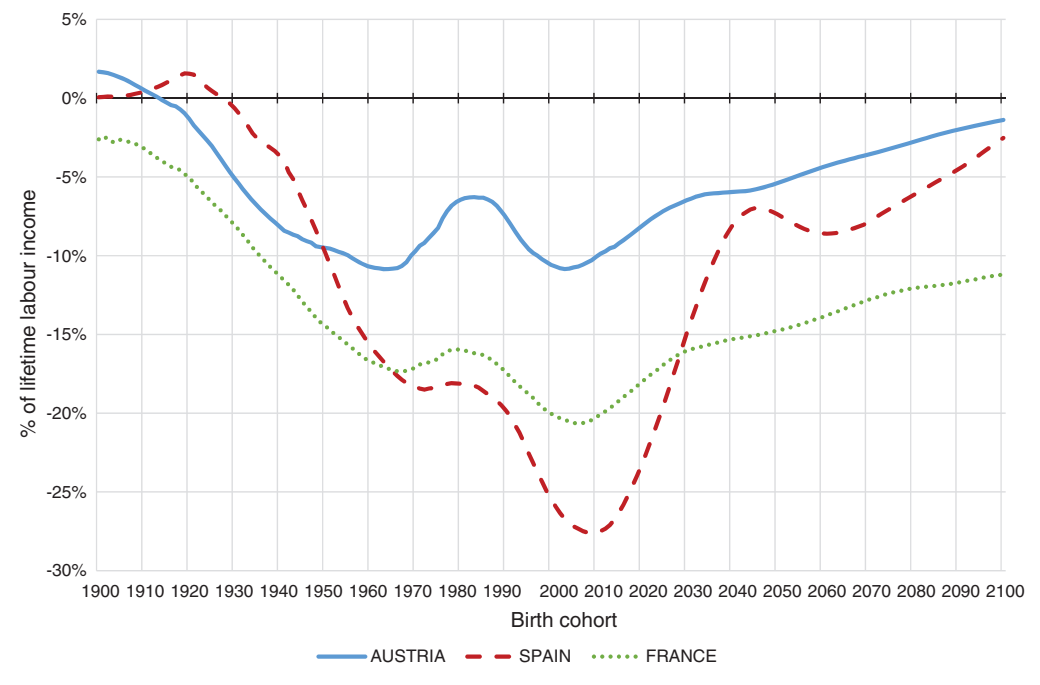

The decline is larger in Spain because it is amplified by the rapid change in the population structure and by the expansion of the educational system (see Figure 3 ). The downward tendency continues in all countries up to the cohorts born in 1963 (Austria), 1967 (France), and 1972 (Spain). For the cohorts born in the 10-20 years thereafter, the net effect increases because the benefits they receive from public education help to offset their losses attributable to pensions and health care. In Spain, where the expansion of the education system was delayed, an increase in the net effect is not observed. In all three countries, the subsequent birth cohorts have decreasing net present values, primarily as a result of the large increase in lifetimediscounted social security contributions and the modest decrease in corresponding pension benefits. The peak loss is observed for the 2003 birth cohort in Austria, amounting to $10.8 \%$ of lifetime labour earnings. The analogous figures for the other countries are a loss of $20.7 \%$ for the 2006 birth cohort in France and a loss of $27.6 \%$ for the 2009 birth cohort in Spain. For the later cohorts, relative gains in education and health benefits can be seen in all three countries, most notably in Spain; and the net impact of public transfers becomes decreasingly negative for each successive generation. For the cohort born in 2100, the net losses due to public transfers are estimated at $1.4 \%, 11.1 \%$, and $2.5 \%$ of lifetime labour income in Austria, France, and Spain, respectively.

In line with the observed differences within countries in the present value of benefits and taxes of each public programme displayed in Figures 2-4, the shape of the total net effect by birth cohort follows a similar pattern in all three countries. In Spain, however, the evolution is much more volatile because the country's demographic transition has been more dramatic. This pattern suggests that in Spain, 
the higher degree of redistribution of income from younger to older generations is induced by public policy. Another distinct feature of the evolution of the Spanish present values is that they occur later than in the other two countries. This pattern reflects both the later introduction of the welfare state and the more gradual expansion of public programmes in Spain. In particular, the positive effects of public education are postponed in Spain, even though they reach higher values once they are achieved. In France, there seems to be a greater degree of intergenerational fairness, as the fluctuations in net present values are smaller. However, as Figure 5 shows, public programmes provide lower returns for future generations in France than in the other two countries. Of all of the generations in all three countries, the Spanish cohorts born between 2000 and 2017 suffer the greatest losses, amounting more than $25 \%$ of lifetime labour income.

Overall, our results indicate that the positive effect of public education never offsets the negative effects of public pensions and health care for the generations born after 1927 in the three countries we focus on. This finding contrasts with the results obtained in Bommier et al. (2010) for the US, who found that cohorts born between 1947 and 2060 attain positive net present values. The differences in these findings can be explained in part by the lower benefit levels of the American pension system. Moreover, when comparing our results with those of Bommier et al. (2010), it is important to note that we included general equilibrium effects in our analysis. For example, the future interest rate used in the calculation of the present value at birth of benefits and taxes is not constant in our framework, but instead results from the general equilibrium model, and evolves according to the demand and the supply of capital in each year. The rate oscillated quite a bit in the past due to capital accumulation, which was driven in part by demographic change. From 2060 onwards, the rate stabilises at around 5\%, with slight differences between countries. Higher interest rates give more weight to downward transfers like education, as they imply that the benefits people receive earlier in life have higher values than the taxes they pay later in life. The opposite pattern is observed for a transfer system that redistributes from young to old, such as the pension system. Therefore, a higher interest rate improves the net present value at birth for downward transfers, and worsens it for upward transfers. ${ }^{17}$

\section{Reform scenarios}

As we outlined in the previous sections, our projections indicate that the welfare state system has a substantial fiscal imbalance in the long run if it is to be maintained as assumed in the benchmark scenario. Hence, substantial tax adjustments are required to make the system sustainable. However, such adjustments will lead to

17 Moreover, whereas Bommier et al. (2010) based their analysis on the assumption that health expenditures grow more quickly than productivity, we assume that health costs grow at the same rate as productivity. 
a deterioration in the fiscal balance between generations, and thus to higher levels of intergenerational redistribution and lower levels of intergenerational fairness. In this section, we present different reform scenarios, and assess their capacity to balance the sustainability of the public programmes of the welfare state with intergenerational fairness.

\subsection{Delay in retirement age}

There is a large body of literature on pension system reform. Besides decreasing pension benefits and increasing contributions - both of which are reflected in our baseline scenario - most studies have argued for the postponement of the statutory retirement age. This policy appears to be very effective, as it affects both the revenue side and the expenditure side of the system by increasing the period when people are making contributions and decreasing the period when people are receiving pension benefits. This measure is likely to be especially effective if it is implemented at a time when relatively large numbers of baby boomers are retiring. Moreover, raising the retirement age seems desirable given that people are living longer and entering the labour market later as they spend more time in education (see Lee (2016)).

We have simulated the effects of delaying the retirement age from 65 to 67, and from 69 to 71 . The increase in the retirement age is implemented step-wise from the year 2020 to the year 2040. Figure 6 reflects the variation in the pension expenditure to GDP ratio with respect to the baseline in the three counterfactual scenarios. After 2020, the year in which the reform is first introduced, public pension expenditures decrease in the three countries as a percentage of GDP. Further reductions are observed in the following 20 years as the policy change is being implemented. After 2040, the difference with respect to the baseline shrinks progressively into the distant future, although a negative net effect still remains. The pattern varies somewhat across the three countries. For example, the changes are the smallest in Austria, and are the longest lasting in France.

The sequences are similar for the three chosen retirement ages within each country, with the later ages always having a stronger effect. When retirement is delayed by two years, the ratio decreases up to $10-12 \%$ in the most critical years. Moreover, the ratio decreases up to $18-24 \%$ if retirement is delayed by four years, and up to $27-36 \%$ if the new retirement age is set at 71 . The largest effects occur in Spain, where the percentage change in pension expenditure to GDP is further reduced in the 2070s if retirement is postponed to age 71 . This pattern is attributable to the dissipation of the effects of the baby boom generation in that decade.

These changes derived from the postponement of the retirement age translate into variations in the net present value of public programmes presented in the previous section. Figure 7 displays the change in the total net present value of the combined pensions, education, and health systems for cohorts born from 1950 to 2100 relative to the baseline scenario. Although the main impact of a policy of delaying retirement is expected to be on the present value of taxes paid and benefits 
Figure 6:

Changes in pension expenditure/GDP by delaying the retirement age
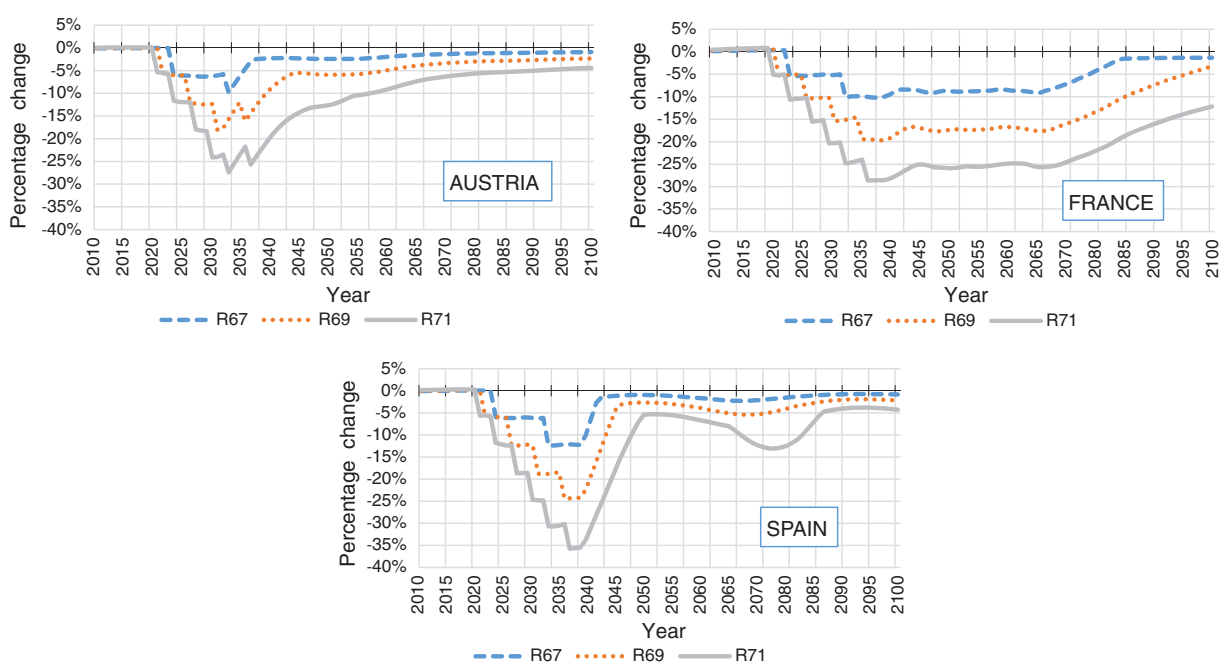

received from the pension system, several effects on pensions and contributions may offset each other, and could thus minimise the net result for this programme. On the one hand, delaying retirement implies that pension benefits are received for a smaller number of years and contributions are paid for a larger number of years. Both factors push down the net present value at birth of participating in the pension system. On the other hand, the general equilibrium nature of the model, together with the assumption that the system is balanced every year on a PAYG basis, entail a reduction of the contribution rates and a potential increase in benefits received. In this case, the result is an improvement in the net present value of public pensions.

The evolution of the variations in the different reform scenarios shown in Figure 7 also reflects the changes in the other public programmes (education and health care) due to general equilibrium effects. Overall, for any postponement of retirement, members of the older generations who are near the end of their working lives at the time the policy is implemented - roughly, those born between 1950 and 1980 lose as a result of the reform. Future generations - or those who are very young when the reform is first implemented in Austria and Spain - also lose from the delay in retirement. However, the younger generations benefit, as they obtain a higher net present value at birth compared to the baseline. How large these changes in benefits and losses are depends on the number of years the age of retirement is postponed. In the most extreme scenario (retirement at age 71), the maximum losses for the earlier generations are between $2 \%$ and $3 \%$ of lifetime labour income, and are larger for the future generations (around 5\% in Austria and France, and around 
Figure 7:

Change in net present value of public transfers under different retirement regimes
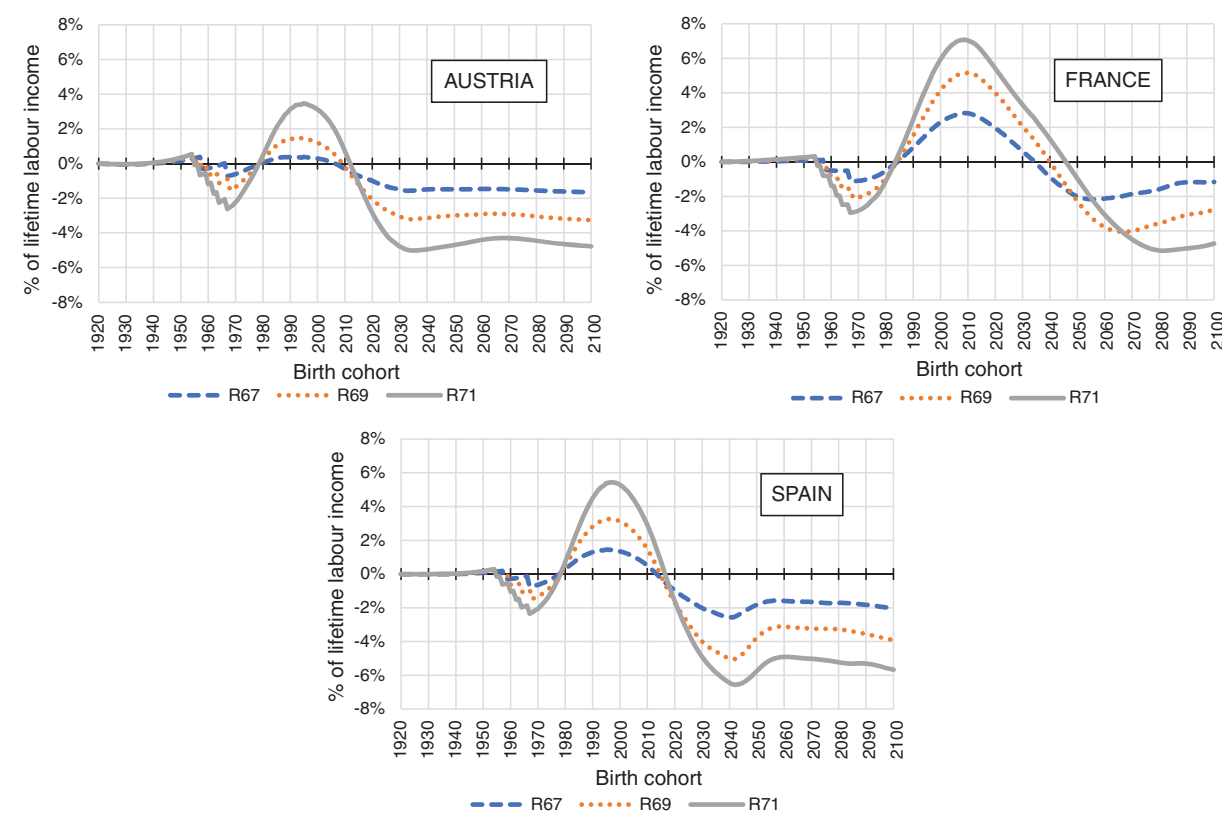

7\% in Spain). The largest gains amount to 3.5\% of labour earnings for the 1995 birth cohort in Austria; 5.4\% for the 1997 birth cohort in Spain; and 7.1\% for the generation born in 2009 in France.

When we compare the three countries, we see differences not only in the levels of maximum gains and losses with respect to the baseline, but in the time paths when these changes occur. In Austria, the generations who gain from the increase in the retirement age are those born from 1980 to 2006 in the age 67 scenario, those born from 1979 to 2009 in the age 69 scenario, and those born from 1979 to 2011 in the age 71 scenario. In France, the corresponding cohorts who gain from the reform are those born from 1985 to 2034 (spreading to 5-6 more years for each additional step in the retirement age increase). In Spain, the corresponding cohorts who benefit from the reform are those born between 1978 and 2013 (1979-2014 and 19792016, respectively). Hence, the benefits of the reform are spread out across more generations in France than in other countries. Recall that the maximum contribution rate for the social security system is set at $35 \%$, and that once that limit is reached, any adjustments that are made must come from reducing pension benefits. Because France is ageing more slowly than the other two countries, this limit is reached later in France (and is never reached in the age 71 scenario), which explains the previous results. 
Table 2:

Changes in tax rates from financing health using different tax bases

\begin{tabular}{|c|c|c|c|c|c|c|c|}
\hline \multirow{3}{*}{$\begin{array}{l}\text { Change in } \\
\text { share of GDP } \\
\text { of tax } \\
\text { revenues of }\end{array}$} & \multirow[b]{3}{*}{ Year } & \multicolumn{6}{|c|}{ Tax financing health } \\
\hline & & \multicolumn{3}{|c|}{ Consumption tax } & \multicolumn{3}{|c|}{ Labour income tax } \\
\hline & & Austria & France & Spain & Austria & France & Spain \\
\hline \multirow[t]{2}{*}{ Consumption } & 2050 & 5.9 & 5.9 & 6.4 & -4.7 & -5.7 & -5.4 \\
\hline & 2100 & 7.0 & 6.5 & 6.2 & -5.6 & -6.3 & -5.4 \\
\hline \multirow{2}{*}{$\begin{array}{l}\text { Labour } \\
\text { income }\end{array}$} & 2050 & -5.1 & -4.4 & -4.3 & 5.6 & 7.3 & 7.5 \\
\hline & 2100 & -6.0 & -4.8 & -4.3 & 6.9 & 8.2 & 7.7 \\
\hline \multirow{2}{*}{$\begin{array}{l}\text { Capital } \\
\text { income }\end{array}$} & 2050 & -1.1 & -2.1 & -2.5 & -1.1 & -2.2 & -2.5 \\
\hline & 2100 & -1.3 & -2.2 & -2.5 & -1.3 & -2.2 & -2.5 \\
\hline
\end{tabular}

\subsection{Changing the tax base}

While public expenditures mainly flow to children and the elderly, taxes are mostly paid by the working population; although some taxes are paid by children (consumption tax through parents) and the elderly (consumption and capital income tax). This suggests that one way to alleviate the pressures governments are facing as a result of the ageing process is to make changes to the tax bases. As Table 1 shows, the tax bundle used to finance public health and education differs to some extent in each of the countries in our study. Since this may be among the factors that influence the results we obtained, we developed two alternative scenarios that we use to investigate to what extent the choice of a different tax mix alters our results so far. To keep things simple, we focus on only one public programme, and implement a gradual reform by using one tax base as the funding source, instead of a mix of the three, as we assume in the baseline.

In particular, the policy reform we analyse consists of changing the tax base to finance future health care spending from the year 2020 onwards, and it is implemented progressively over a period of 20 years. We consider two policy options: financing future health expenditures using only taxes on consumption; and, alternatively, using only taxes on labour income. In both policy options, the specific tax rate chosen increases while the other two tax rates decrease. We decided not to use the capital income tax in these counterfactuals because of the high deadweight losses this policy would imply.

Table 2 reports the percentage change in all tax revenues (of consumption, capital income, and labour income) as a share of GDP and with respect to the baseline as a result of changing the tax base for financing health care. The results are displayed for the years 2050 and 2100; i.e. at two points in time after the reform has been fully carried out and the strongest effects have been realised. If health is financed 
by taxing only consumption goods, the corresponding tax revenues on consumption are projected to increase compared to the baseline scenario in which a mix of the three tax bases is used by 5.9\% of GDP in Austria and France and by $6.4 \%$ of GDP in Spain in 2050. The analogous values in 2100 are somewhat higher for the first two countries and are slightly lower for Spain. Both the capital income and the labour income tax revenues decline relative to the benchmark case in the decades following the full implementation of the reform. The labour income tax revenues decrease from between 4.3\% of GDP in Spain to 6.0\% of GDP in Austria; while the adjustments in capital income tax revenues are smaller, ranging from $1.1 \%$ of GDP in Austria to 2.5\% of GDP in Spain.

If health care is financed by taxing only labour income, the increases in tax revenues for this specific tax are slightly lower than in the first reform using consumption taxes in Austria, but are higher in Spain and in France in particular, reaching $8.2 \%$ of GDP in 2100. Tax revenues from consumption taxes are reduced by between $4.7 \%$ and $6.3 \%$ of GDP, with a stronger effect in France. The effects on revenues from capital income are similar to those in the previous scenario.

The effects on the total net present value at birth of pensions, health, and education are shown in Figure 8, which displays the changes with respect to the baseline. For all three countries, there are large gains for all generations if public health is financed exclusively through labour income. This is because a tax on labour income depletes more capital per worker than a tax on consumption. As a consequence, the interest rate increases, which gives more weight to transfers received earlier in life (education) than later in life (pensions and health care), and thus increases net benefits. In Austria, these benefits monotonically increase with birth cohorts, and the maximum gains amount to $11.7 \%$ of lifetime labour income for the generation born in 2100. In France, the benefits increase up to the 2048 birth cohort (with net gains of $13.5 \%$ of lifetime earnings compared to the baseline), and then remain rather constant, reaching $13.8 \%$ of lifetime labour income for the last cohort born in 2100. The evolution of net present values is somewhat different in Spain, where a maximum difference of $14 \%$ is observed for the generation born in 2011. Thereafter, the difference decreases to $10.2 \%$ for the 2042 birth cohort, increases modestly to $11.1 \%$ for the 2061 birth cohort, and then decreases again to $9.2 \%$ for the 2100 birth cohort.

Alternatively, if the tax base used to finance public health care consists of consumption taxes, the generations born between 1976 and 2023 in Austria gain compared to the baseline. Similarly, the 1972-2047 birth cohorts in France and the 1979-2030 birth cohorts in Spain benefit from this policy scenario. The largest gains are observed for the generations born in 2002-2004 (depending on the country), and are highest in Spain (11\% of lifetime earnings) and lowest in Austria (4.9\% of lifetime earnings). In France, the maximum gains correspond to $8 \%$ of lifetime labour income. The other generations lose, and the future generations in particular. The losses for the 2100 birth cohort amount to $4.6 \%, 1.6 \%$, and $6.6 \%$ of lifetime earnings in Austria, France, and Spain, respectively. The losses for the previous cohorts are much smaller, reaching less than $1 \%$ (in absolute terms) in all cases. 
Figure 8:

Difference in the net present value of public transfers when changing tax bases. Financing health care with consumption taxes (left) and with labour income taxes (right)
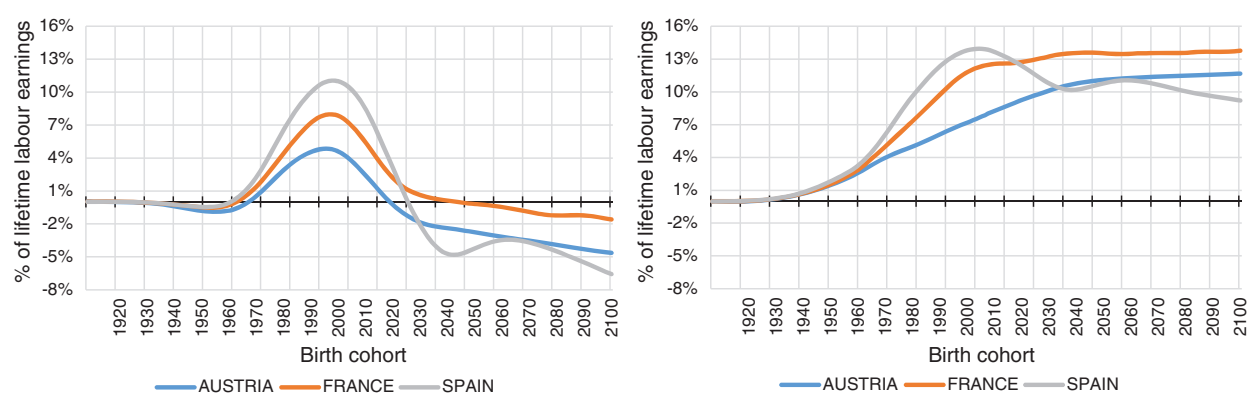

\subsection{Fixed education}

One of the most distinguishing features of the model we used to derive the previous results is the degree of heterogeneity with respect to the educational level of the population. There are important differences in the educational composition of workers across countries, which generate diverse patterns of behaviour, and which in turn lead to distinct patterns of economic development.

Table 3 reports information on the actual and predicted educational composition for several birth cohorts in Austria, France, and Spain. We consider three levels of education based on the UNESCO classification: ISCED 0-2 (lower secondary education or less), ISCED 3-4 (upper secondary education), and ISCED 5+ (tertiary education). The pace of the educational transition differs in each country. The share of the 1980 birth cohort who have attained tertiary education is 44\% in France, 24\% in Austria, and 33\% in Spain. The shares of the 1980 birth cohort with ISCED 0-2 and ISCED 3-4 educational levels are, respectively, 15\% and 61\% in Austria, $15 \%$ and $41 \%$ in France, and $28 \%$ and $39 \%$ in Spain. This pattern reflects the fact that the modern educational system was introduced later in Spain than in Austria and France. These differences between the three countries shrink by 2040, and it is assumed that by the end of the century, all individuals will attain at least upper secondary education. The share of the 2100 birth cohort projected to attain tertiary education is five points higher in France than in Austria, and is two points higher in Austria than in Spain.

In order to assess the impact of education on our results, we develop a scenario in which the educational attainment is held constant. In the experiment, we simulate the effects of stopping the educational transition by fixing the educational levels achieved by the 1980 cohort, who completed their education in the base year. 
Table 3:

Percentage of population by educational level by birth cohort in Austria, France, and Spain

\begin{tabular}{|c|c|c|c|c|c|c|c|c|c|}
\hline \multirow{2}{*}{$\begin{array}{c}\text { Country } \\
\text { Education level (ISCED) }\end{array}$} & \multicolumn{3}{|c|}{ Austria } & \multicolumn{3}{|c|}{ France } & \multicolumn{3}{|c|}{ Spain } \\
\hline & 0-2 & $3-4$ & $5+$ & 0-2 & $3-4$ & $5+$ & 0-2 & $3-4$ & $5+$ \\
\hline \multicolumn{10}{|l|}{ Birth cohort } \\
\hline 1980 & 15 & 61 & 24 & 15 & 41 & 44 & 28 & 39 & 33 \\
\hline 2040 & 1 & 30 & 70 & 0 & 23 & 77 & 1 & 31 & 68 \\
\hline 2100 & 0 & 22 & 78 & 0 & 17 & 83 & 0 & 24 & 76 \\
\hline
\end{tabular}

Source: WIC Data Explorer (2015).

Figure 9:

Difference in net PV of public transfers with fixed education

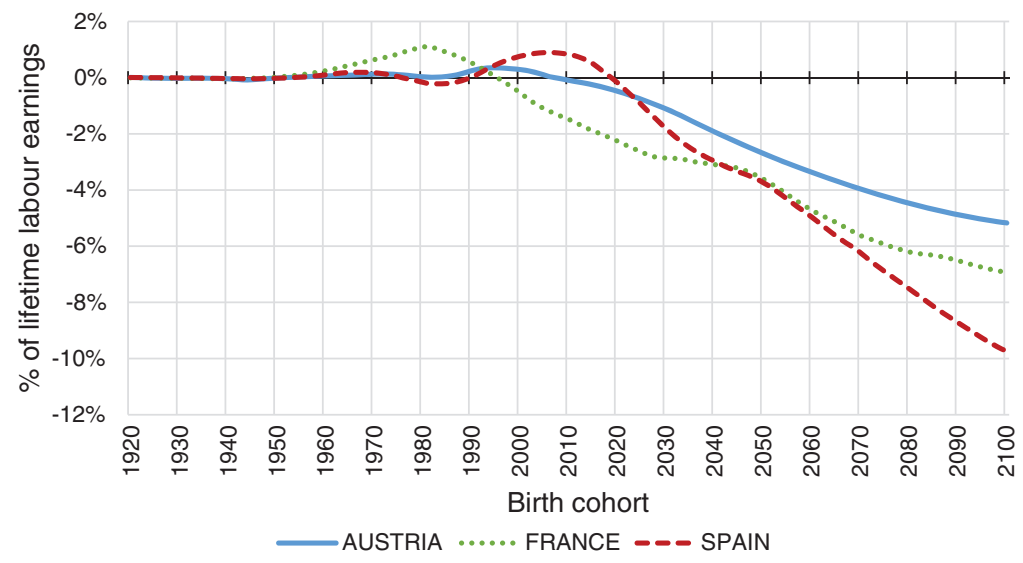

Figure 9 shows the impact of the fixed-education scenario on the net present value at birth of public programmes for cohorts born between 1920 and 2100 in Austria, France, and Spain. In all three countries, some cohorts realise net fiscal gains from this scenario (those born between 1952 and 2007 in Austria, between 1949 and 1995 in France, and between 1990 and 2018 in Spain), but the positive effects are small. ${ }^{18}$ If educational attainment is fixed at the 1980 birth cohort levels, these generations will have to pay lower taxes for the education of their descendants, but they will

\footnotetext{
18 For the 1954-1975 birth cohorts in Spain, a very small (less than $0.2 \%$ ) positive change in the net present value can be observed.
} 
also lose some benefits, as they will have received less education. In this case, the former effect dominates. For previous generations, there is little variation with respect to the benchmark scenario. Future generations are projected to lose from the interruption of the educational transition in all three countries, as they will have lower educational levels, and thus will receive lower returns from education in the labour market. The largest losses are in Spain and France. For the cohort born in 2050, the loss in the present value of lifetime labour income is $2.7 \%$ in Austria, $3.6 \%$ in France, and 3.7\% in Spain. For the cohort born in 2100, the corresponding loss is 5.2\% in Austria, 6.9\% in France, and 9.7\% in Spain.

\section{Discussion}

In this paper, we have analysed the impact of population ageing on the sustainability of public fiscal policy, and we have explored the implications of several reform scenarios, including a delay in the statutory retirement and a change in the tax base for financing health care expenditures.

We have also described the consequences of having different levels of educational attainment in order to assess the effects of education on the results. The analysis focuses on three European countries (Austria, France, and Spain), which differ in terms of the strength of their demographic transition, their path of development, and the generosity of their welfare state programmes.

The results for sustainability show a drastic increase in the shares of public expenditure to GDP for the three main programmes of the welfare state (pensions, education, and health care). The total expenditures on these programmes range from 26\% (Austria), 25\% (France), and 19\% (Spain) in 2015 to $36-37 \%$ in 2050. This shift is mostly driven by the change in the ratio of benefit recipients to taxpayers, which is directly linked to the demographic dependency ratio. The tax adjustments needed to ensure the sustainability of these programmes affect different generations very differently.

Figure 10 summarises the main results, showing the net present value of public transfers (pensions, education, and health care) for the distinct scenarios. We have included only one of the reform scenarios for delaying the retirement age (namely, the most extreme one in which retirement is postponed from age 65 to age 71 ; see the red line). The other two simulations (from age 67 to age 69) yielded milder effects in the same direction. We have also included the scenarios in which health care is fully financed through consumption (yellow dotted line) and labour income taxes (solid grey line) in the future; and, finally, the fixed education scenario (dashed green line).

We found that in the three countries, the best scenario for improving the net present value at birth of public transfers is financing health care with labour income taxes. All generations gain from this policy reform. In the scenario in which public health is funded with consumption taxes, the results are less clear, as there are winners and losers from the reform in terms of net present value at birth. In all 
Figure 10:

Net present value of public transfers under different scenarios
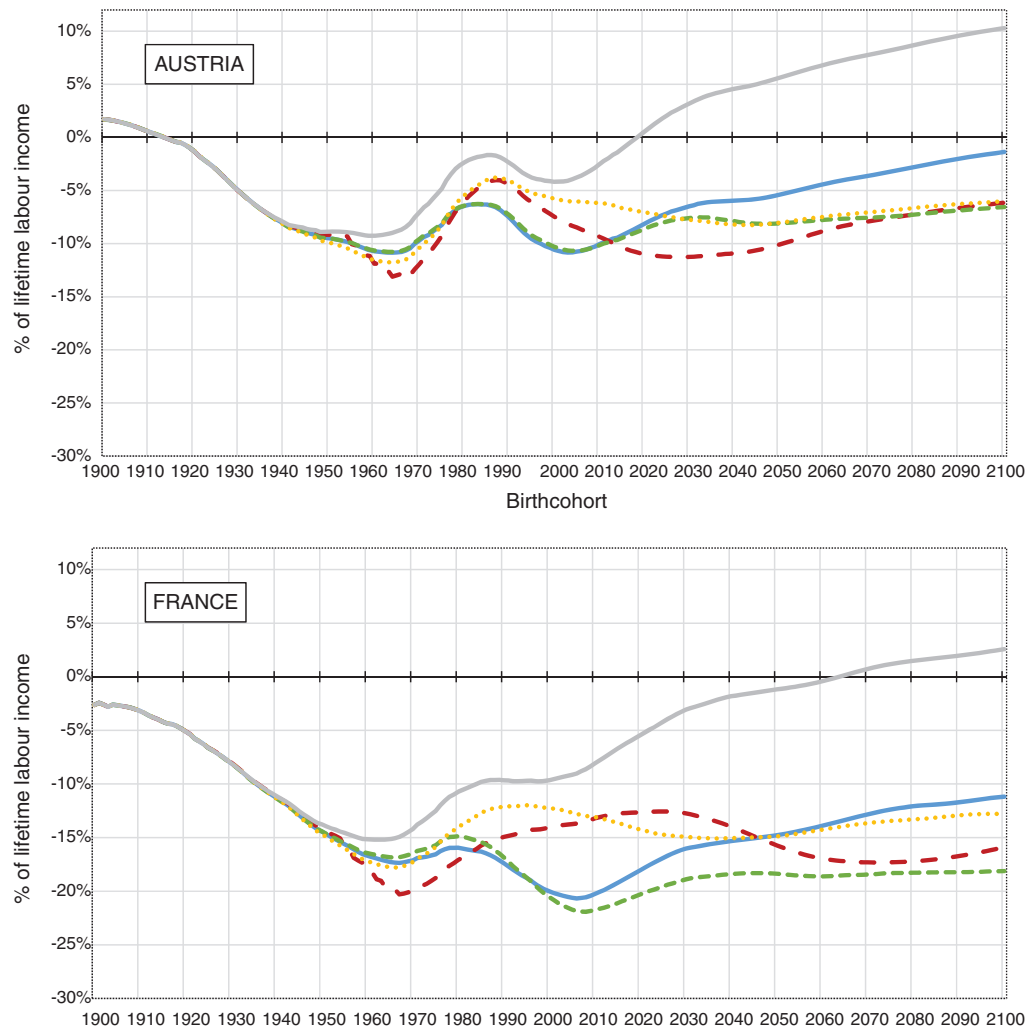

Birth cohort

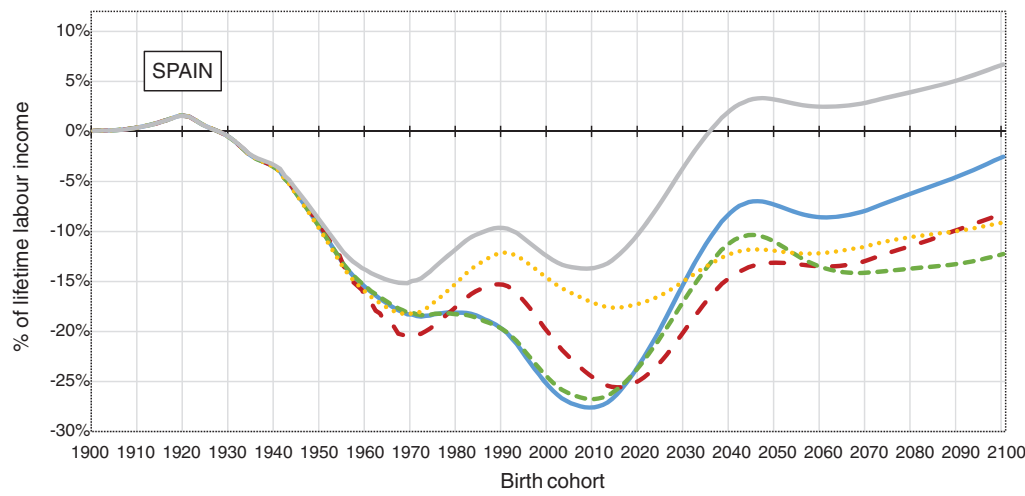

Baseline - - Retirement - - Education $\ldots .$. Consumption tax $\longrightarrow$ Labour tax 
of the other scenarios (different from the "labour tax"), we found that the reform is good for some cohorts, but that future generations always lose compared to the baseline.

In terms of intergenerational fairness, our results suggest that Spain is the country in which public policies in the benchmark scenario generate the highest levels of intergenerational redistribution from younger to older individuals, and Austria is the country in which this redistribution effect is minimal. The reforms that involve changing the tax base seem to improve intergenerational fairness in France and in Spain in particular, as they flatten the evolution of present values across cohorts.

\section{Acknowledgments}

This project has received institutional support from the European Union's Seventh Framework Programme for research, technological development and demonstration (AGENTA project, grant agreement no: 613247), the Spanish Science and Technology System (Project number ECO2016-78991-R MINECO/FEDER and the Red de excelencia SIMBIEN ECO2015-71981-REDT), the Catalan Government Science Network (Project number SGR2014-1257) and the network Xarxa de Referència en $R+D+I$ en Economia i Polítiques Públiques (XREPP).

\section{References}

Abío, G., C. Patxot, E. Rentería and G. Souto 2015. Taking care of our elderly and our children: Towards a balanced welfare state? In Family and sustainable development, eds M. Gas-Aixendri, R. Cavallotti. Thomson Reuters/Aranzadi.

Auerbach, A. J. and L. J. Kotlikoff 1987. Dynamic fiscal policy. Cambridge: Cambridge University Press.

Bommier, A. and R. D. Lee 2003. Overlapping generations models with realistic demography. Journal of Population Economics 16(1): 135-160.

Bommier, A., R. D. Lee, T. Miller and S. Zuber 2010. Who wins and who loses? Public transfer accounts for US generations born 1850 to 2090. Population and Development Review 36(1): 1-26.

Bonin, H. 2001. Generational accounting. Theory and application (Population economics series). Berlin: Springer.

Donehower, G. 2014. Incorporating gender and time use into NTA: National Time Transfer Accounts methodology, Version 4 (unpublished manuscript). Berkeley: University of California at Berkeley, Department of Demography.

Gal, R. I. and J. Monostori 2014. Indicators of economic sustainability and intergenerational fairness. Deliverable 6.1, AGENTA project. Download from: http://www.agenta-project. eu/Jacomo/upload/publications/d-6.1-submitted.pdf 
Istenič, T., A. Šeme, B. Hammer, A. Lotrič Dolinar, and J. Sambt 2016. The European NTA Manual. Deliverable 1.4, AGENTA project. Download from: http://www.agenta-project. eu/en/public-deliverables.htm.

Istenič, T., A. Šeme, B. Hammer, A. Lotrič Dolinar and J. Sambt 2017. European National Transfer Accounts. Available at: http://www.wittgensteincentre.org/ntadata.

Lee, R. D. 2016. Macroeconomics, ageing and growth. In Handbook of the economics of population aging. Volume 1B, eds J. Piggott and A. Woodland, 59-118. Amsterdam: Elsevier.

Lee, R. D. and A. Mason 2011. Population aging and the generational economy: A global perspective. Cheltenham UK - Northampton MA: Edward Elgar.

Lee, R., D. McCarthy, J. Sefton and J. Sambt 2017. Full generational accounts: What do we give to the next generation? Population and Development Review 43(4): 695-720.

OECD 2017. Pension spending (indicator). DOI: 10.1787/a041f4ef-en (Accessed on November 2017)

Patxot, C., E. Rentería, M. Sánchez-Romero and G. Souto 2012. Measuring the balance of government intervention on forward and backward family transfers using NTA estimates: the modified Lee arrows. International Tax and Public Finance 19: 442-461.

Sánchez-Romero, M., G. Abío and C. Patxot 2017. Overlapping Generations-General Equilibrium (OLG-CGE) Model: Underlying Assumptions and Projections. Deliverable 5.5, AGENTA project. Download from: http://www.agenta-project.eu/en/public-deliverables. htm

Sánchez-Romero, M., G. Abío, C. Patxot and G. Souto 2018. Contribution of demography to economic growth. SERIEs. Journal of the Spanish Economic Association 9(1): 27-64.

UN 2013. National Transfer Accounts manual: Measuring and analysing the generational economy. New York: United Nations Population Division, Department of Economics and Social Affairs.

Wittgenstein Centre for Demography and Global Human Capital 2015. Wittgenstein Centre Data Explorer Version 1.2. Available at: http://www.wittgensteincentre.org/dataexplorer. Yaari, M. E. 1965. Uncertain Lifetime, Life Insurance, and the Theory of the Consumer. The Review of Economic Studies 32(2): 137-150. 


\section{Appendix: Key inputs of the projection model}

\section{Figure A.1:}

NTA age cross-sectional profiles of public education expenditure by educational level for Austria, France, and Spain (year 2010)

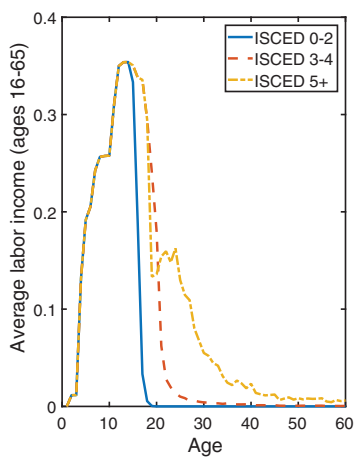

(a) Austria

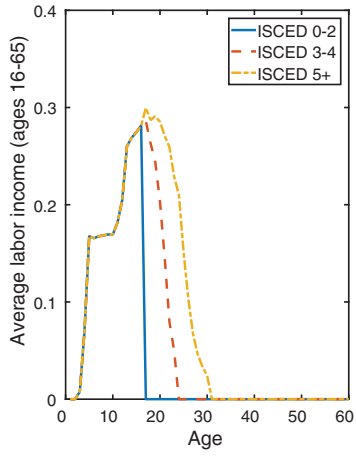

(b) France

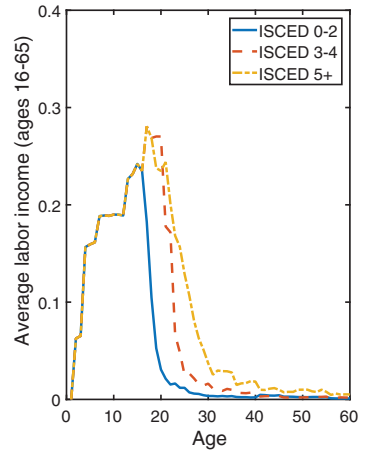

(c) Spain

Source: Istenič et al. $(2016,2017)$ and author's calculations.

\section{Figure A.2:}

NTA age cross-sectional profiles (year 2010) and demographic dependency ratio for Austria, France, and Spain

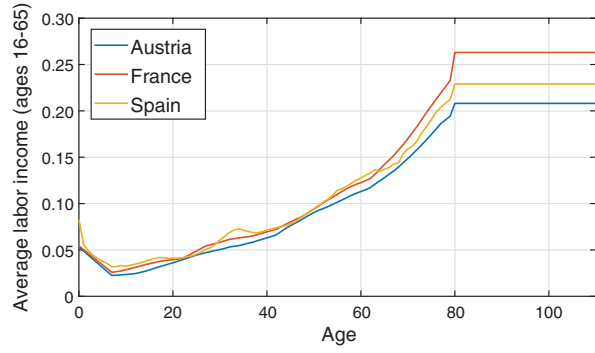

(a) Public health care expenditure

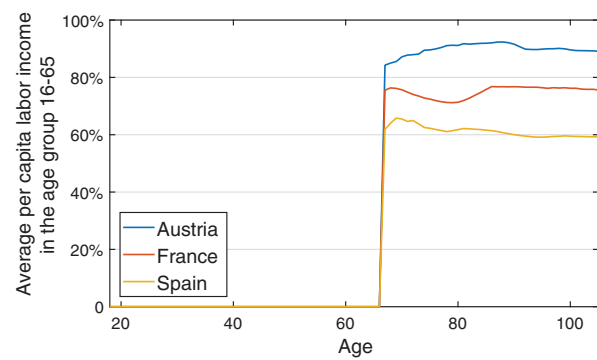

(b) Public pension benefits

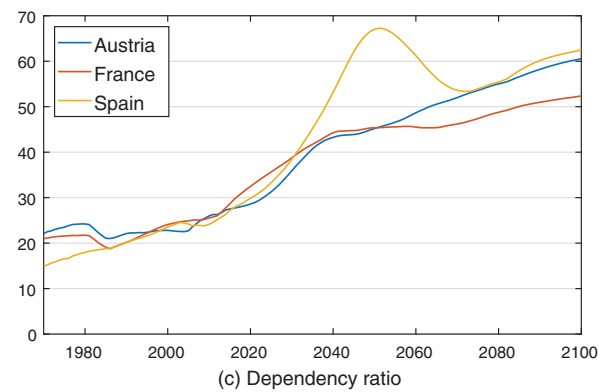

Source: (a-b) Istenič et al. (2016, 2017); (c) author's calculations following European Commission (2018) assumptions. 
The figures above summarise some of the key inputs of the projection model. Figure A.1 shows public expenditures on education by age in the year 2010 in the three countries. The level of expenditures is higher in Austria, reflecting that country's distinct educational transition path. Panels (a) and (b) in Figure A.2 show the NTA age profiles for public health and pension expenditures. The age patterns look quite similar in the three countries, although there are significant differences in levels. France has the highest health expenditures, followed by Spain. In the case of pensions, public benefits are more generous in Austria and less generous in Spain. Panel (c) summarises the differences in demographic patterns by showing the annual evolution of the dependency ratio. France has the best situation in terms of demographic dependency, in part because it has a higher fertility rate than the other two countries. A large baby boom effect can also be observed in Spain. 